\title{
The Spatial Dynamics of Sanitation Conditions in Matebeleland South Province of Zimbabwe
}

\author{
Evans Chazireni", Effel Tembo \\ Department of Physics, Geography and Environmental Science, School of Agriculture and Natural Sciences, Great Zimbabwe University, \\ Masvingo, Zimbabwe
}

Email address:

echazi@yahoo.com (E. Chazireni)

${ }^{*}$ Corresponding author

\section{To cite this article:}

Evans Chazireni, Effel Tembo. The Spatial Dynamics of Sanitation Conditions in Matebeleland South Province of Zimbabwe. European Journal of Clinical and Biomedical Sciences. Vol. 3, No. 6, 2017, pp. 115-119. doi: 10.11648/j.ejcbs.20170306.13

Received: October 4, 2017; Accepted: November 16, 2017; Published: December 5, 2017

\begin{abstract}
Conditions of sanitation remain a major challenge in Zimbabwe and particularly in Matebeleland South province. One of the sanitation challenges faced in the country is that of inequality. There are severe spatial inequalities in sanitation conditions in the districts of Matebeleland South province of Zimbabwe. This paper examines the spatial patterns of sanitation conditions in Matebeleland South province of Zimbabwe. Primary data used in this study was collected through questionnaires. The analysis of the data was done through the multiple component index method. The calculated multiple component indices were used to rank the districts according to the level of health conditions.
\end{abstract}

Keywords: Sanitation, Multiple Component, Matebeleland, Geometric Mean and Index

\section{Introduction}

Sanitation is a critical component of health. Sanitation refers to any facilities that promote proper disposal of human and animal wastes, proper use of toilet and avoiding open space defecation [11]. It involves the promotion of hygiene through the prevention of human contact with hazards of wastes especially faeces, by proper treatment and disposal of the waste. Sanitation encompasses the means and measures necessary for improving and promoting health and wellbeing of the people. The distribution of sanitation services is affected by different factors which include physical, social, economic and political. Generally, the global distribution is characterised by inequality in space. About four people in ten in the world do not have access to proper toilet facilities and of these, two thirds live in Asia and Africa [13]. Poor sanitation leads to different types of disease. Poor sanitation, hygiene and water are responsible for about $50 \%$ of Childhood deaths [12]. Poor sanitation may increase the spread of faeco-oral diseases such diarrhoeal, trachoma, soil transmitted helminthiases and schistosomiasis since these are basically water related diseases. Diarrhoeal diseases are the most important of the faeco-oral diseases globally, causing around 1.6-2.5 million deaths annually, many of them among children under 5 years old living in developing countries [6] [7]. This paper

\section{Study Area}

Matebeleland South is one of the ten provinces of Zimbabwe. It is bounded on the on the south by South Africa and on the southwest by Botswana. It has total area of 54172 $\mathrm{km}^{2}$ and a population 683893 [14]. Gwanda is the provincial capital. Beitbridge is also a town in the province. Beitbridge is on the boarder to South Africa. It is therefore the home of different languages such as Venda, Shona and Shangani. The province is one of the most arid provinces of Zimbabwe because of its location in the Limpopo Basin. The province experiences low epileptic precipitation of about $500 \mathrm{~mm}$ with areas such as Beitbridge receiving as low as $453 \mathrm{~mm}$ with average temperatures of $40^{\circ} \mathrm{C}$ in summer and $13^{\circ} \mathrm{C}$ in winter [5]. The province experiences a number of challenges which include gold panning, deforestation, invasion by alien species, stream bank cultivation, siltation, soil erosion among others [2]. Such challenges negatively impact on socioeconomic development of the province and health and sanitation are not spared. The province has seven 
administrative districts which are Beitbridge, Bulilima, Gwanda, Insiza, Mangwe, Matobo and Umzingwane. Figure 1 shows the location of the administrative districts. The administrative districts are used as spatial units of analyses for the examination of the spatial aspects of sanitation in the province.

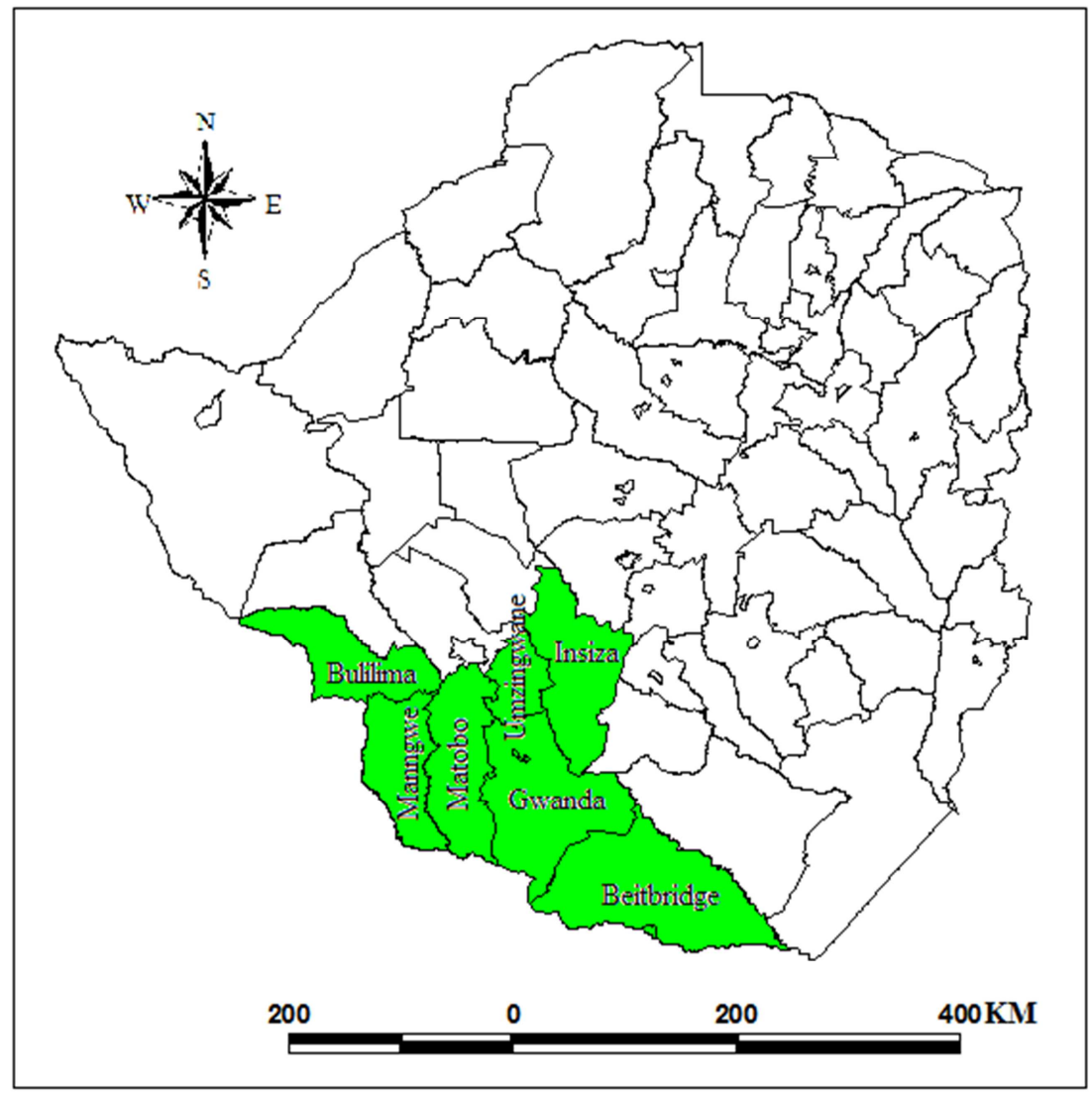

Figure 1. The map showing administrative districts in of Matebeleland South province.

\section{Methodology}

Primary data were gathered and used in this study. The data was collected through questionnaires. A total of 50 questionnaires were completed in each district. Both purposive and simple random sampling were used to get the questionnaires to the respondents. Purposive sampling was used to get people with appropriate knowledge while simple random sampling was used to ensure that people in the targeted population were to have the same probability of being included in the sample. To achieve the simple random sampling, the national registration numbers of the people in the targeted population were used and then Microsoft Spread Sheet was used to do the simple random sampling. To determine the conditions of sanitation conditions in each district data was collected on nine indicators/variables. The indicators on which data was collected are: percentage of children under $<36$ months with diarrhoea in the previous two weeks, quantity of water used per capita per day, percentage of child caregivers with appropriate hand washing behaviour, food preparers with appropriate hand washing behaviour, percentage of population using hygienic sanitation facilities, percentage of households with year-round access to water, percentage of households with access to a sanitation facility, percentage of recurrent costs for water supply services provided by community served and percentage of constructed water supply systems managed by the communities served.

To analyse the spatial variation in sanitation in Matebeleland South province, the multiple index method was used. The multiple component indices were used to rank the districts according to conditions of sanitation prevailing in the districts. The multiple component index is the aggregation of the indices derived from the indicator values of the water and sanitation in the districts of Matebeleland South province. The multiple component index is sometimes called the geometric mean. The geometric mean is a type of average, which indicates the central tendency of a set of observations by using the product of their values (unlike the arithmetic mean which uses their sum). The geometric mean of a data set $\left(k_{1} . k_{2} . k_{3} . k_{4} \ldots k_{n}\right)$ is given by: Geometric mean $=$ $\sqrt[n]{k 1 . k 2 . k 3 . k 4 \ldots k n}$. For example, the geometric mean of three numbers, say 2, 4 and 8 , is the cube root of their product; that is $=4$. When the calculated multiple component index value (geometric mean value) is high such as in the case of Gwanda in Figure 2 it means that the conditions of sanitation in that district are good. On the other hand, the low multiple component index value means that the sanitation conditions are poor. 


\section{Results and Discussion}

As displayed in Figure 2, there are severe disparities in the levels of sanitation in Matebeleland South province of Zimbabwe. The numbers in brackets in the map legend represent the multiple component index values for each district in terms of sanitation provision. It is evident from the map (Figure 2) that there is inequality in the provision of sanitation in the province. These inequalities are influenced by several factors which are culturally, social, political and economic.

The districts with comparatively the highest levels of overall socioeconomic development, such as Gwanda and Beitbridge (Figure 2) are districts that have the towns in the province. The towns are Gwanda in Gwanda district and Beitbrigde in Beitbridge district. Districts which are purely rural and are far away from the urban areas such as Mangwe and Bulilima have comparatively the lowest levels of sanitation conditions in the province. The crucial function played by urban areas in the development of health and sanitation of the population is manifested in this situation. Findings from this study are in agreement with other scholars [1] [3] [8] who hold that people living in urban areas have better conditions of health compared to their rural counterparts. Urban areas generally have more hospitals, more health personnel, better transport, better education systems and their populations usually have higher incomes and political dominance. Such conditions serve as essential ingredients for better health and sanitation. In a national spatial system, urban areas have high levels of socioeconomic and political development; therefore, constitute the core region of a country [4]. Health and sanitation are components of development and therefore district having some urban inclination generally better sanitation.

It has also emerged from Figure 2 that, generally there is a tendency for districts with closely related multiple component indices to be closely located near each other in the province. This obeys [9] first law of geography which states that "everything is related to everything else, but near things are more related than distant things" In other words, there is generally a tendency for similar things to be close to each other. This tends to imply that sanitation conditions tend to vary fairly slowly over the districts in Matebeleland South province. The change is not abrupt in the sanitation conditions. In this regard positive spatial autocorrelation is operative in which similar sanitation conditions tend to be located near each other. The spatial distribution of sanitation in the province is such that, from Gwanda district which has the highest multiple component index sanitation generally declines gradually both in the South Western direction and North Eastern direction

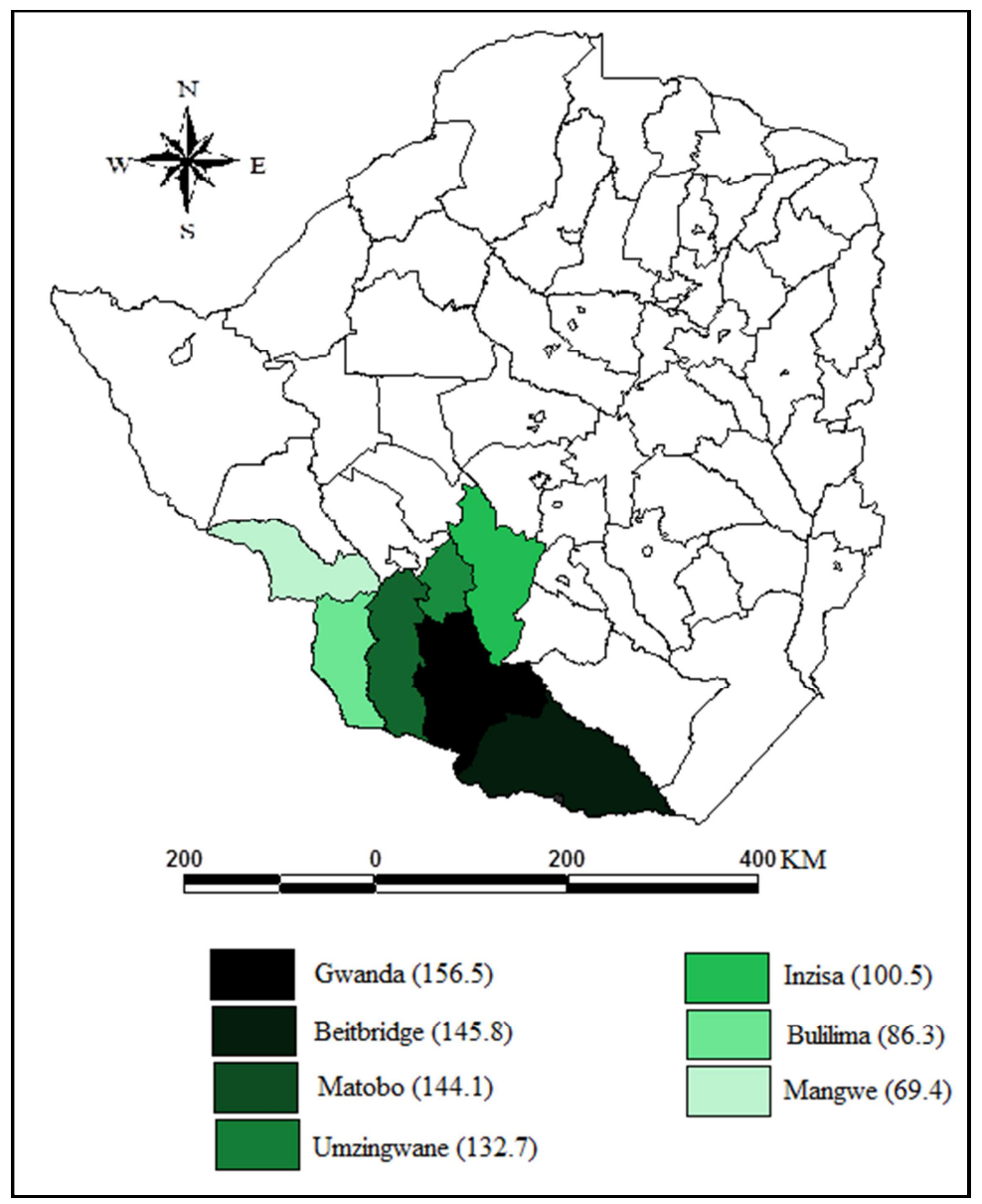

Figure 2. Spatial pattern in the provision of sanitation in Matebeleland South. 


\section{Recommendation}

The following recommendations were made based on the findings of this study:

(a) Promotion of community health clubs.

Community health clubs are crucial for the development and improvement of sanitation services in Matebeleland South. These clubs may spread ways on how to live a health life in rural deprived communities. Therefore, the spread of sanitary diseases due to unhygienic life styles would be minimised in some ways. Health clubs also enhance understanding through the spread of education.

(b) Promotion cost effective infrastructural development.

The major problem facing Zimbabwe is the development of infrastructure. Most health infrastructure was developed during colonial era. Few infrastructural developments was undertaken after independence. Many rural areas in Zimbabwe lack toilet and clean water supplies. Some of these households live with incomes which are below the poverty datum line which makes it difficult for such households to construct sanitary infrastructure for themselves. Government and other stakeholders need to construct low cost sanitary infrastructure which is mainly based on local resources.

(c) Special health zones.

This involves the selection of deprived areas with the intention to make significant health improvements in that region. This helps in the reduction of the inequalities between areas with good health (sanitation) and those with poor health (sanitation). Currently, there are no special health zones in Zimbabwe. Zimbabwe and particularly Matebeleland South province may need such zones. It is important to have areas designated as special zones as a means of health improvement strategy. Special health zones can be used to reduce disparities in sanitation between different districts in the province.

(d) Improvements in health policies

A review of public health is needed. The government should consult with the public to come up with efficient working public legislation on health. A research conducted by [10] revealed that Public Health Act is poorly implemented and the public health system somewhat ineffective, with frustration over the lack of priority given to public health and over new risks that are not being managed. It was perceived that the Public Health Act and its penalties are not well known [10]. Therefore, government as a whole should be giving higher priority to public health, to make known and implement current law, even while it undertakes the review to update it. There was strong consensus for the rights to health to be included in the Act and for a rights based approach, and a call for inclusion of responsibilities for health, including duties on individuals not to compromise rights of others. The rights that people expected to see in law included rights to social determinants like water, food and housing; to health services and medicines, and to public information.

\section{Conclusion}

It emerged from this research that there are severe disparities in conditions of sanitation in Matebeleland South province. There are some districts which recorded comparatively good sanitation conditions while others manifested poor sanitation conditions. The spatial pattern of sanitation conditions are chiefly influenced by the humancentred force, the urban influence. Urban districts or those close to urban centres generally have far much better sanitation conditions compared to those with rural inclination. These differences are attributed to several factors which are political, economic and social. Certain recommendations were proposed for the improvement of sanitation conditions in the province. It is hoped that if such recommendations are taken into account, inequalities in sanitation conditions among the districts in the province would be reduced and the general state of sanitation condition in the province would improve.

\section{References}

[1] Chazireni, E. 2015. The temporospatial dimension of health in Zimbabwe, Unpublished PhD Thesis. Department of Geography. Pretoria: University of South Africa.

[2] Environmental Management Agency, 2016. Zimbabwe: Environmental Profile. Government Publishers, Harare.

[3] Li, Y. and Wei, Y. H. 2010. A Spatial-Temporal Analysis of Health Care and Mortality Inequalities in China. Eurasian Geography and Economics, 51 (6): 767-787.

[4] Hachman, S. 2014. Regional development in Zimbabwe, International Journal of Development Studies, 7 (6). 221-232.

[5] Holland, J. 2014. Redefining Agroecological regions of Zimbabwe. Environmental Science Journal, (5). 179-190.

[6] Kosek. M, Bern. C \& Guerrant R. L. (2003) The global burden of diarrhoeal disease, as estimated from studies published between 1992 and 2000. Bull World Health Organ. 81:197-204.

[7] Mathers, C. D., Lopez, A. D \& Murray. C. J. L. 2001. The Burden of Disease and Mortality by Condition. New York: Oxford University Press.

[8] Montgomery, M. R. 2009. Urban Poverty and Health in Developing Countries. Population Bulletin 2): 1-15.

[9] Tobler W. 1970. A computer movie simulating urban growth in the Detroit region. Economic Geography Journal, 46 (2): 234-240.

[10] Training and Research Support Centre (2011). Community views on public health law and practice in Zimbabwe. Government Publishers, Harare.

[11] United Nations' Children's Emergency Fund. (2013) Water, sanitation and hygiene in health care Facilities Status in lowand middle-income countries and way forward. World Health Organisation. Geneva. 
[12] Victoria, C. G. (2008). Maternal and Child undernutrition consequences for adult health and human capital. Lancet. 371: 340-358.

[13] World Health Organisation (2008). Global burden of disease. World Health Organisation. Geneva.
[14] Zimbabwe National Statistical Agency. 2012. Published national reports of the 2012 population census. Government Publishers, Harare. 